\title{
Effect of children on the sound environment in fast-food restaurants
}

\author{
Qi Meng ${ }^{\mathrm{a}, \mathrm{b}}$, Shanshan Liu ${ }^{\mathrm{a}, \mathrm{c}}$, Jian Kang ${ }^{\mathrm{a}, \mathrm{b}^{*}}$ \\ ${ }^{a}$ Key Laboratory of Cold Region Urban and Rural Human Settlement Environment Science and \\ Technology, Ministry of Industry and Information Technology, School of Architecture, Harbin \\ Institute of Technology, Harbin 150001, 66 West Dazhi Street, Nan Gang District, Harbin, China \\ ${ }^{\mathrm{b}} U C L$ Institute for Environmental Design and Engineering, University College London (UCL), \\ London WC1H ONN, UK \\ 'Shenzhen Capol Engineerng Design Co., Ltd, Shenzhen 518038, 4/F, Yingfu Building, Shihua Rd, \\ Futian Bonded Zone, Shenzhen, China \\ ${ }^{*}$ Corresponding Author
}

\begin{abstract}
While an increasing number of studies are examining the effect of the sound environment in restaurants, this study is the first to examine the effect of children on the sound environment of dining areas. We measured children's behaviour and the sound pressure level in a dining area and investigated acoustic comfort and sound source to ascertain the influence of the number of children, behaviour, and gender combinations while playing on the sound environment of a typical fast-food restaurant in Harbin City, China. The results demonstrate that, first, with fewer than four children, the sound pressure level (SPL) increases significantly when the number of children increases (e.g., by $2.8 \mathrm{dBA}$ per child). However, when the number of children exceeds four, the SPL is almost stabilised. Second, sound sources heard by people in the dining area can also be influenced by the number of children; the sound of communication among children increased by $12 \%$ and then decreased by $20 \%$ as the number of children increased. Finally, the number of children affects acoustic comfort by 2.2 (on a 5 point scale) due to the duration of the Max SPL, and by 1.0 due to the percentage of screaming and communicating. These results demonstrate that the sound environment can be improved by changing the number of children and their combination groups.
\end{abstract}

Keywords: Children, playground, combinations, sound environment, sound source, fast-food restaurant

2020 Applied Acoustics

Date received: Received 13 June 2019 Date accepted: 27 December 2019

Publish online: 9 January 2020 


\section{INTRODUCTION}

Restaurants can be divided into five types based on the level of consumption: quick-service restaurants (QSR or fast-food), fast-casual, midscale, moderate (or casual), and fine dining (or upscale) [1]. Of these, fast-food restaurants have gradually become the main choice for eating out, owing to the convenient and fast dining experience that they offer [2]. In selecting fast-food restaurants, customers focus on the restaurant environment [3], particularly the sound environment, as well as factors such as taste [4]. Some previous studies have noted that a restaurant's sound environment significantly affects the customer's will to return and to recommend the restaurant [5]. Another indoor study found that the sound environment (e.g., acoustic comfort) affects a customer's evaluation of their overall satisfaction with the restaurant [6-8]. Another study noted that a restaurant's sound environment affects how people feel about the taste of the food [9]. In terms of sound sources, some studies have noted that the negative evaluation of sound sources in restaurants has a greater impact on potential sources of visitors than positive evaluations [10]. Therefore, it is very important to create a good sound environment in restaurants, particularly fast-food restaurants.

Some previous studies have also demonstrated that the evaluation of the sound environment can be affected by multiple factors (e.g., spaces, human factors, and the sound environment itself). Different crowd densities in restaurants have an impact on the sound environment as well as on customers' acoustic comfort [11]. Moreover, while age and gender do not affect the judgment of acoustic comfort, the length of the visit and activities do [12]. The social characteristics of the customer, such as income, education, and occupation, and so on, also affect acoustic comfort [13]. Different types of restaurant may use different types of background music, which will also have a certain impact on sound comfort $[14,15]$. Of these music types, classical concerts encourage people to spend more [16]. The noise of the equipment in the restaurant has an adverse effect on customers' acoustic comfort [11]. People's conversation behaviour at dinner is also affected by the sound environment [18], with, for example, the cocktail party effect, which means people concentrate on interesting conversation and ignore other sounds in restaurants, and this significantly affects customers' acoustic comfort [19]. However, the influence of children's activities on the sound environment and acoustic comfort has not been considered in previous studies.

Although the effects of children's activities on restaurants' sound environment are rarely mentioned, children-directed marketing is being used by more fast-food restaurants [20]. In terms of children's age characteristics, some studies have demonstrated that playing with peers of the same age can effectively eliminate a child's loneliness [21]; thus, many parents take their children to the playground. In terms of gender characteristics, in social problem-solving strategies, girls are more peaceful than boys [22]; the latter expand from small groups into large groups to form peer groups, while girls tend to form individual small groups [23]. There is no obvious difference between boys and girls in terms of communicating with others [24], but girls are more sensitive to the status of people in the group [23]. The gender of the children and their playmates also affects their engagement in activities [25]. Although children have not yet fully developed gender stereotypes, they are more likely to play with children of the same sex [26].

Based on the above, this study aims to ascertain the impact of children's activities in the playground on the SPL and acoustic comfort of fast-food restaurants. First, the influence of the number of children and behaviour combinations while playing on the sound environment were examined. Then, the relationship between children's characteristics and the perception of sound sources were examined. Finally, the effect of children's characteristics on the acoustic comfort of a dining space with a playground was investigated. A typical fast-food restaurant in Harbin city, China, was selected as the case site. The SPL and observation of children's behaviour were measured, while acoustic comfort and sound sources were investigated using questionnaires.

\section{METHODS}

\subsection{Case Study Site}

Numerous previous studies have found that children's playgrounds in fast-food restaurants usually have one of two typical layouts (Fig. 1) [27]: either the playground is located in the dining area or it is located outside of the dining area. In the first arrangement, there is usually no wall between the children's playground and the dining area so that sound transmission cannot be effectively prevented [28]. Under this arrangement, the children's playground has a greater effect on the sound environment of the dining area. To investigate the influence of children's playgrounds on the sound environment, this paper selected a case study site featuring the first arrangement.

A Kentucky Fried Chicken (KFC) outlet in Daoli District, Harbin, China, was selected as the 
study site. Within this KFC outlet, furniture divides the second floor into two main dining areas, one of which contains a children's playground (Fig. 2). There are 13 tables in this dining area, which can accommodate 33 to 40 people. The children's playground is located in one corner of the dining area, with an area of approximately 14 square meters, accounting for 20 per cent of the dining area. A 1.2-meter-high fence divides the children's playground from the dining area. The decoration materials of the dining area and children's playground can be found in Table 1.

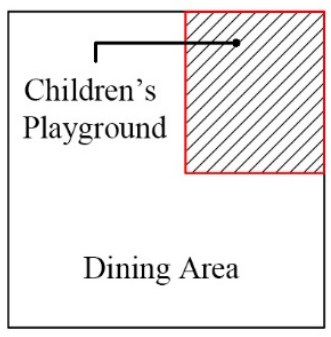

Children's Playground in Dining Area

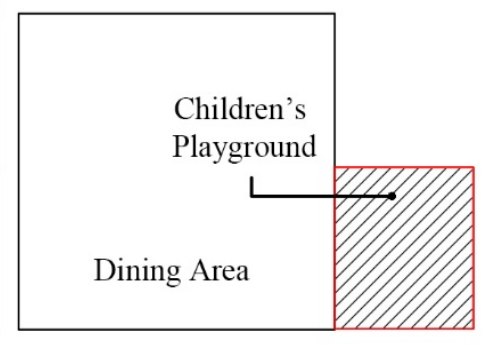

Children's Playground out of Dining Area

Fig. 1 Two types of layout mode

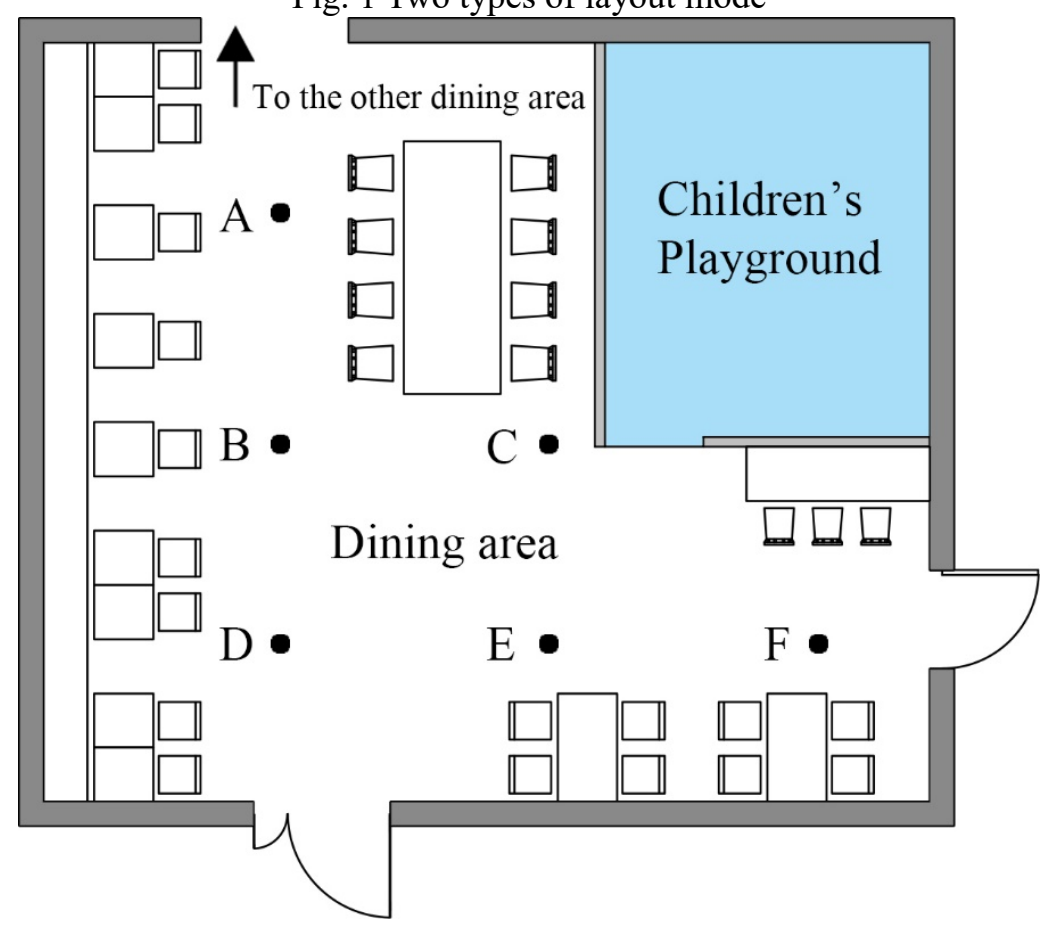

Fig. 2 Plan of case site 1:100

Table 1 Interior materials of ceilings, walls, and floors in the case study site

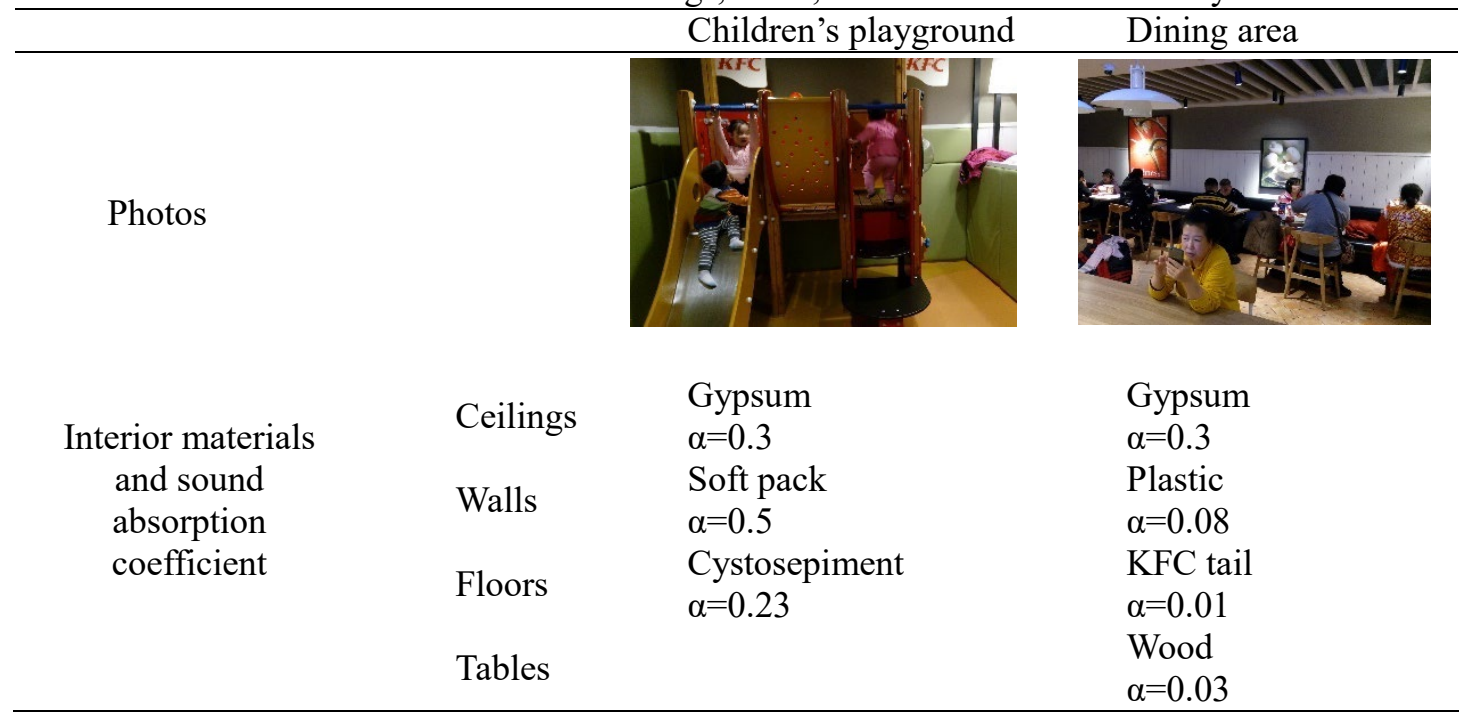




\subsection{Observation of Children's Behaviour}

After gaining permission from their parents, an HD video camera was used to record the behaviours of children playing in the playground. Observations of the children's characteristics in the case site were carried out every weekend and lasted one year (from Nov. 2017 to Oct. 2018) because of the following reasons. It was found that there was no significant difference in the number and behaviour of users between weekdays and weekends at KFC, as well as the SPL and the types of background music. However, as children usually go to the case site at the weekend, it is easier to investigate the different number of children at the weekend. As our previous investigation had shown that this is the time of highest usage of the playground, the observation period lasted from $10.00 \mathrm{am}$ to $6.00 \mathrm{pm}$. Children aged between three and six years were selected for observation, as previous studies have demonstrated that this age group can operate independently in playgrounds [29]. Furthermore, for safety reasons, the children's playground does not recommend usage by very young children, while children over six years gradually decrease their interest in this kind of play and instead prefer games that challenge their intelligence [30].

As children require some time to adapt to the playground environment [31], the observation began at least one minute after the child had entered or exited the playground. Some previous studies have demonstrated that children's concentration increases with age [32]. In the observation, children in the playground could usually maintain stable activity for eight to ten minutes. Therefore, the observation time for each playing types was set at five minutes. During the observation, children sometimes suddenly ran out of the playground. In such cases, observation continued so long as the child was not separated from the activities in the playground. If the child disengaged from the activities, however, the observation would cease.

According to the observation of children's performance in the activities, the combination of their activities can be divided into three basic types: centralised, partially centralised, and dispersal. The centralised combination means that all children in the field form a group to play together. The dispersal combination means that no playgroup is formed; instead, every child takes care of himself and plays alone. It should be explained that the partially centralised combination means that some of the children in the playground form a playgroup, while other children play alone.

\subsection{Measurement of Acoustic Environment}

The SPL was measured at the same time as the observation of the children's behaviour. The data lasting for $3-5 \mathrm{~min}$ and the interval between the two data was at least $1 \mathrm{~min}$. The sound-level meter was set 1 meter away from the wall and main reflector and 1.2-1.5 meters from the ground [33]. The data were measured every second using fast-style and A-weight [34]. At the survey site, to avoid measurement errors, six measurement points (A-F) were first selected in the initial SPL measurement, and every point was at least 2 meters apart. The results of each point were not significantly different from the other points [35]. Therefore, point $C$ was selected in the formal investigation, to avoid the influence of the users, as fewer users sit nearby the children's playground. In order to avoid the influence of people sitting close to the measurement point, the measurement was carried out only when there was no user nearby.

In the analysis, we took the data average as the average SPL and the instantaneous Max value as the Max SPL and the Min value as the Min SPL, because the children's sudden shouts are at a high frequency and a high decibel level, which may influence both the instantaneous SPL and acoustic comfort. Simultaneously, the duration of each shout or loud communication was relatively short. Taking the instantaneous Max value as the Max SPL can reflect the change in the sound environment more truly and accurately.

As reverberation time may influence the sound feeling in an indoor space [36, 37], we also took this factor into account. Based on the investigation, the number of people in the dining area was generally between 6 and 35. From the calculation using the Eyring formula, the $T_{30}(500 \mathrm{~Hz})$ was 0.52 ( 6 users) to $0.40 \mathrm{~s}$ ( 35 users). The difference in the reverberation time (RT) was only $0.12 \mathrm{~s}$, and therefore, the effect of RT based on different crowd density was not considered in this paper [18].

\subsection{Questionnaire survey}

In this section, we introduce the length of survey time (2.4.1), selection and criteria for volunteer participants (2.4.2), survey and investigation of acoustic comfort (2.4.3), and sound sources (2.4.4).

2.4.1. Length of survey time. After initial observations at the case site, it was found that people in fast-food restaurants engage in various activities such as having a brief rest, waiting for meals, 
dining, and resting after dinner, and so on [18], although the main activity is eating. The length of time spent in fast-food restaurants also varies [38]. After more than 850 minutes of observation, the main behaviour affecting stay time is rest, with people in fast-food restaurants usually spending between 10-25 minutes eating, most of which is concentrated in approximately 15 minutes. Therefore, this study selected 15 minutes as the period of time within which to investigate the sound source and acoustic comfort.

2.4.2. Selection and criteria for volunteers. The users at the case site can be generally divided into two groups. The first group includes parents who have a relationship with the children, and the second group includes people who are not related to the children. From the first group, the relationships between the parents and children may influence their evaluation of a sound environment. Meanwhile, teenagers and young adults are the typical service object of fast-food restaurants, and they usually have higher expectations for the restaurant environment. That being the case, 25 university volunteers (aged 20 to 24 years) were selected, with relatively equal numbers of females (12) and males (13). As some studies have noted that sound perceptions may vary by gender [39], the genders of volunteers were balanced to avoid the influence of gender. Participants were asked to investigate the sound source and acoustic comfort in the restaurant by filling out questionnaires. They were just told the aims of this project are to record sound sources and acoustic comfort, to ensure that they did not pay too much attention to the children's voice. After arriving at the case site, they were given five minutes to adapt to the new environment to allow them to settle and judge the environment relatively accurately. To avoid habituation caused by a long stay, each participant recorded observations for no more than an hour. To ensure that the fast-food restaurant experience was authentic and that participants' feelings replicated real-life while conducting the questionnaire, volunteers were free to engage in all activities usually conducted in the KFC outlet, such as dining, playing on their mobile phones, and chatting with friends, and so on. Then, the number of each sound source in the questionnaire and the percentage of the sound source to the total sound source was given in each period. In this way, the impact of the sound source on the volunteers was expressed.

2.4.3. Acoustic comfort survey. A five-level scale was used to survey acoustic comfort [40]: $1=$ very uncomfortable; $2=$ uncomfortable; $3=$ neither uncomfortable nor comfortable; $4=$ comfortable; and $5=$ very comfortable [41]. During the survey period, volunteers were asked to record the time and acoustic comfort, as well as the factors influencing their evaluation of comfort. According to the changing characteristics of the children's behaviour in the playground, it was determined that volunteers would generally be required to record randomly at four to six-time points every 15 minutes. The selection of such intervals ensured that there would be sufficient records in each period, and avoided the effect of too many subjective surveys on the results of the records. In the analysis, the average value of each data point was used to indicate the acoustic comfort of the period.

2.4.4. Investigation of sound sources. In the survey, volunteers were asked to record the sound sources they heard at each time point. Repeated sound sources need to be recorded repeatedly, while at the same time recording the sound source that had the greatest impact on them. Based on an investigation of more than 200 persons (in 15 days, accumulated), which were people dining in the fast-food restaurant, 13 typical sound sources in fast-food restaurants with a children's playground were summarised [27]. In this study, all other sources, such as customers' chewing sounds, accounted for less than $1 \%$ and were excluded from the analysis. In the questionnaire, the sound sources were divided into sound source from the restaurant and sound source associated with the playground (Table 2). In this study, 20s was set as one period in the survey, because during this period, volunteers have enough time to record what they hear. Some sources are continuous, and these were considered as occurring once within 20s. There is a distinction between the sound of communication between customers and the sound of communication between parents because customers and parents who accompany children usually have different behavioural patterns and have different effects on acoustic comfort. These criteria were used as data to study the effect of sound sources on acoustic comfort.

\subsection{Statistics and analysis}

SPSS 24.0 [42] was used to establish a database with all the subjective and objective measurements. In this study, linear and nonlinear regression analyses were used to calculate the relationship between the number of children and SPL, as well as among the SPL and acoustic comfort, sound sources, and acoustic comfort. 
Table 2 The main sound sources in case site

\begin{tabular}{|l|l|l|l|}
\hline $\begin{array}{l}\text { Code } \\
\text { name }\end{array}$ & \multicolumn{1}{|c|}{ Type of sound } & $\begin{array}{c}\text { Code } \\
\text { name }\end{array}$ & \multicolumn{1}{c|}{ Type of sound } \\
\hline $\mathrm{a}$ & Background music & $\mathrm{i}$ & $\begin{array}{l}\text { Sound of children beating } \\
\text { instruments }\end{array}$ \\
\hline $\mathrm{b}$ & Sound of equipment & $\mathrm{j}$ & $\begin{array}{l}\text { Sound of children screaming and } \\
\text { crying }\end{array}$ \\
\hline $\mathrm{c}$ & Sound of cleaning & $\mathrm{k}$ & $\begin{array}{l}\text { Sound of communication between } \\
\text { children }\end{array}$ \\
\hline $\mathrm{d}$ & Sound of table and chair friction & $\mathrm{l}$ & $\begin{array}{l}\text { Sound of communication between } \\
\text { children and parents }\end{array}$ \\
\hline $\mathrm{e}$ & $\begin{array}{l}\text { Sound of communication between } \\
\text { staff and customers }\end{array}$ & $\mathrm{m}$ & $\begin{array}{l}\text { Sound of communication between } \\
\text { parents }\end{array}$ \\
\hline $\mathrm{f}$ & $\begin{array}{l}\text { Sound of communication between } \\
\text { customers }\end{array}$ & & \\
\hline $\mathrm{g}$ & Sound of customers playing games & & \\
\hline $\mathrm{h}$ & Footsteps & & \\
\hline
\end{tabular}

\section{RESULTS}

\subsection{Effect of children on the SPL}

In this section, the effect of the number and behavioural combinations of children on the sound environment is explored.

3.1.1. Number of children. The average SPL of the background noise in the dining area was 66.3 dBA (standard deviation 2.1) when there were no children in the playground. When there were no children or only one child in the field, children had little effect on the SPL, with T-test, $p>0.1$. Due to the size of the playground, it was rare for more than eight children to play there at the same time. Therefore, this study investigates numbers of between two to eight children.

A multiple regression analysis was used to analyse the data. The effect of the number of children on the SPL was found to be the highest fitting degree with the cubic curve, $R^{2}=0.992, p$ $<0.001$. As shown in Fig. 3 , the change in the SPL first increases and then tends to stabilise. When there are fewer than four children, the SPL demonstrates a trend of rapid increase. The average SPL is $70.6 \mathrm{dBA}$ when there are two children and increases to $76.2 \mathrm{dBA}$ when there are four children. On average, for every additional child, the SPL increases by $2.8 \mathrm{dBA}$. When there are more than four children in the playground, the change to the SPL tends to stabilise, with an average SPL of 76.8dBA and fluctuating by $0.5 \mathrm{dBA}$.

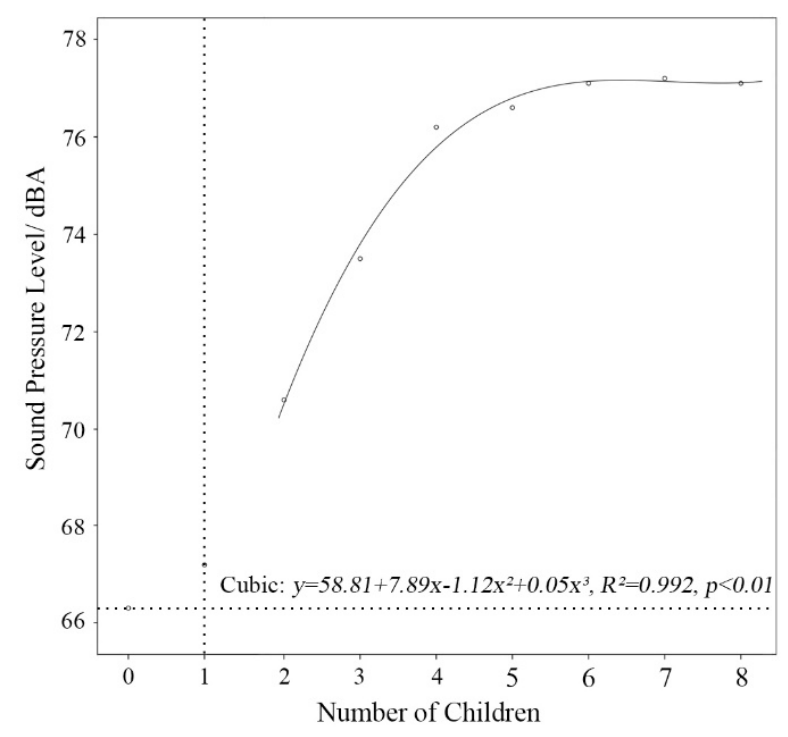

Fig. 3 Effect of the number of children on the average SPL

After analysing the fluctuation range of the SPL for each number of children, the Min SPL was found to increase gradually with the increase in the number of children. With an increase of one child, the SPL increases by $1.8 \mathrm{dBA}$ on average. The Max SPL does not keep increasing. As seen in Fig. 4, the Max SPL usually exceeds 100dBA with fewer than five children. In particular, when 
there are only three children in the playground, the Max SPL reaches nearly 120dBA. When the number exceeds five, the Max SPL decreases significantly. The average Max SPL is 94.7dBA.

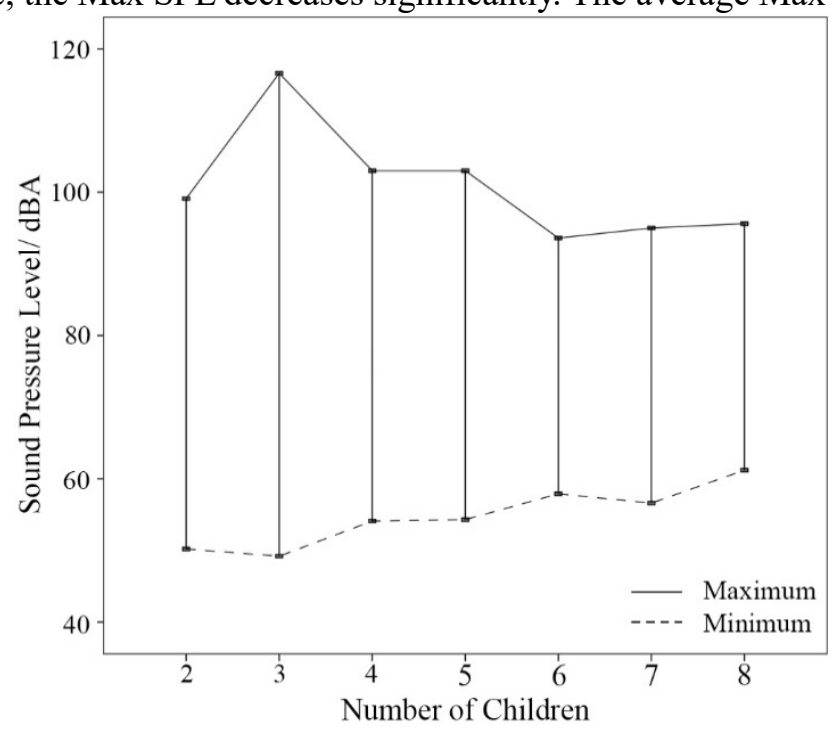

Fig. 4 The effect of the number of children on the Max and Min SPL

3.1.2. Behavioural combinations of children. When there are two children, there are only two possible combination types in the playground: centralised and dispersal. When there are seven or more children, almost no centralised combinations were observed. Therefore, the relationship among the number, the combinations, and the SPL was analysed for cases of three to six children.

When there are three children, there is a $67 \%$ possibility of forming a centralised combination, with only $16.5 \%$ possibility of forming a dispersal combination (Fig. 5). As the number increases, the possibility of forming a dispersal combination gradually increases. When there are six children, the probability of occurrence of the centralised combination is reduced to $13 \%$, and the probability of dispersal combination increases to $61 \%$. The probability of a partially centralised combination decreases with the increase in the number of children. The highest probability of occurrence is with four children, at up to $40 \%$. This combination is widely observed when there are three or more children in the playground.

When the combination is centralised, children need to communicate through language to form and maintain playgroups. Simultaneously, with an increase in the number of children, the difficulty of maintaining a playgroup increases. Children of this age are usually at a stage where language and organisational skills are just beginning to develop $[43,44]$. Thus, it is difficult for them to calmly face the communication challenges posed by a greater number of children, which would require them to communicate in a louder voice or with more intensive language to maintain a stable presence in the group. When there are fewer than four children, the centralised combination prevails. In combination with Fig. 3, this demonstrates that the average SPL increases rapidly as the number of children increases. The trend of the Max SPL changes in Fig. 4 is also related to the combinations. When the number exceeds four, the dispersal combination gradually prevails. In this combination, children no longer require frequent language communication, which stops the average SPL from increasing. When no children suddenly screamed or communicated in the field, most children were able to remain relatively quiet while playing.

It is speculated that when the number of children exceeds eight, the SPL will remain relatively stable. This is because, according to the study of children's behavioural combinations, it can be inferred that more children will lead to a larger percentage of dispersal combinations and communication between children will remain at a low frequency.

\subsection{Effect of children on sound sources}

As the sound level affect can be different, in this section, the effect of children is explored. As seen in Fig. 6, the percentage of sound sources associated with the playground changed with the number of children. As a whole, however, the percentage of each sound source fluctuated within a certain range, and there was no sudden increase or decrease. Overall, the two sources with the largest percentage are $j$-sound of children screaming and crying and $k$-sound of communication among children, while the sources with the lowest percentage are $l$-sound of communication among children and parents and $m$-sound of communication among parents. 


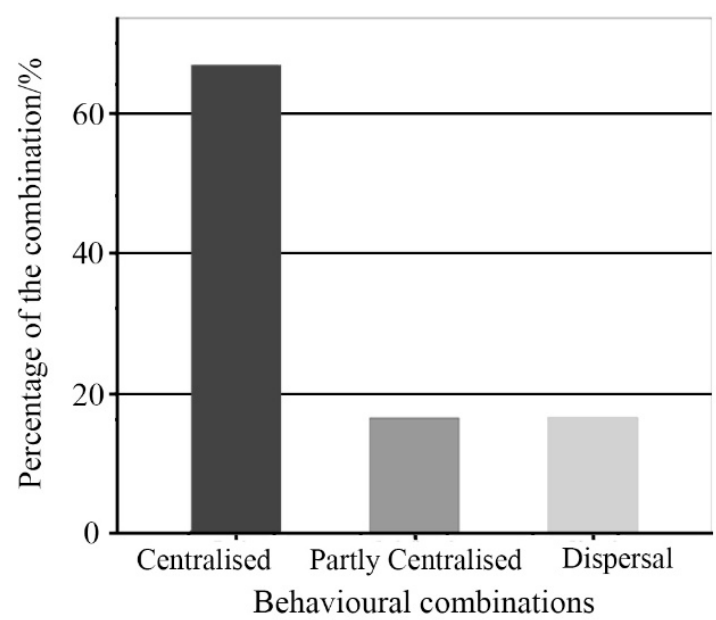

For three Children

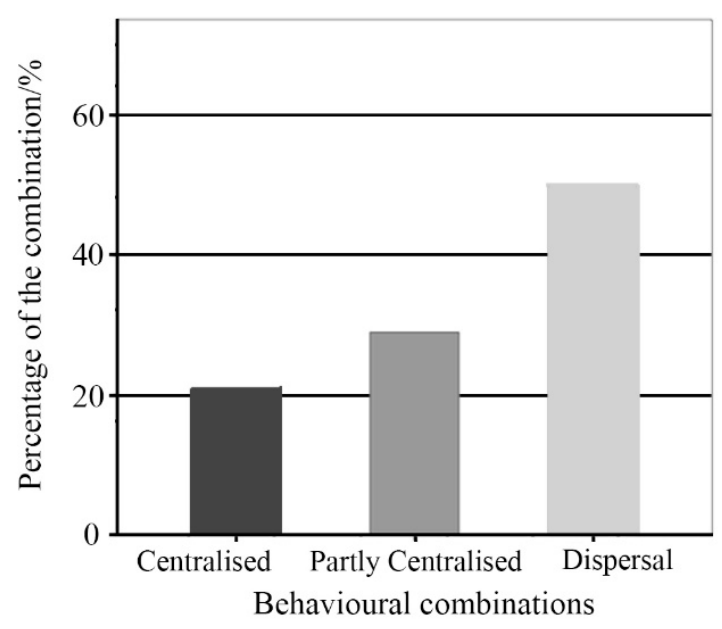

For five Children

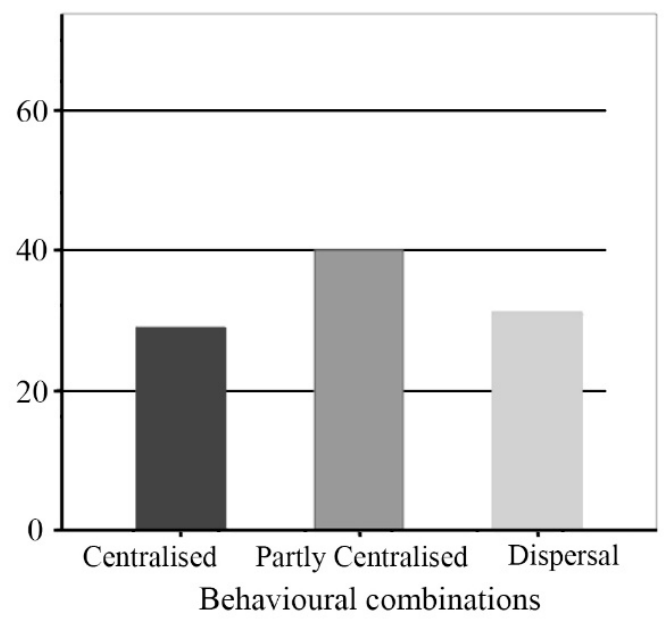

For four Children

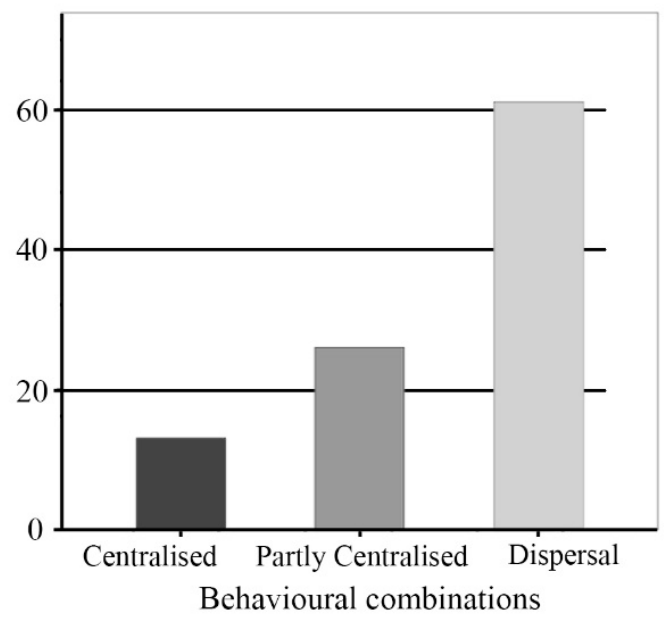

For six Children

Fig. 5 Percentage of each combination

In terms of the sound of children beating instruments, the percentage of $i$-sound of children beating instrument remained stable with an average of $17 \%$. The slide in the playground includes parts that children can tap and rotate to make a sound. In the observation, regardless of the number of children, they were attracted to this setting. With the increase in the number of children, there were some fluctuations in the percentage of $i$-sound of children beating instrument, which may be related to the increase in other sound sources.

In terms of the sound of children screaming and crying, the average percentage of the $j$-sound of children screaming and crying is $28 \%$ (from $25 \%$ to $33 \%$ ), and this fluctuated with the increase in the number of children. Children's screams and cries were often associated with contests over amusement equipment, their heads colliding with instruments while playing, and child-to-child bickering, and so on. It was found that although there was a low probability of these conditions occurring, the proportion of this sound source continued to be high. This phenomenon may be related to this sound source, which can easily attract people's attention and has a great influence on acoustic comfort. A detailed analysis will be conducted in section 3.3.2.

In terms of the sound of communication between children, the percentage of $k$-sound of communication among children first increased and then decreased with the increase in the number of children. When there were five or six children, the percentage was the highest, at $31 \%$ or $33 \%$. The analysis in section 3.1.2 demonstrates that when there are fewer children, they tend towards the centralised combination, which they need to maintain through language communication. However, as the number of children increases, more language communication is required. When there are a large number of children, the combination is mainly of the dispersal type, which does not require very much language communication to maintain. As a result, this sound source presents the changes illustrated in Fig. 5. 


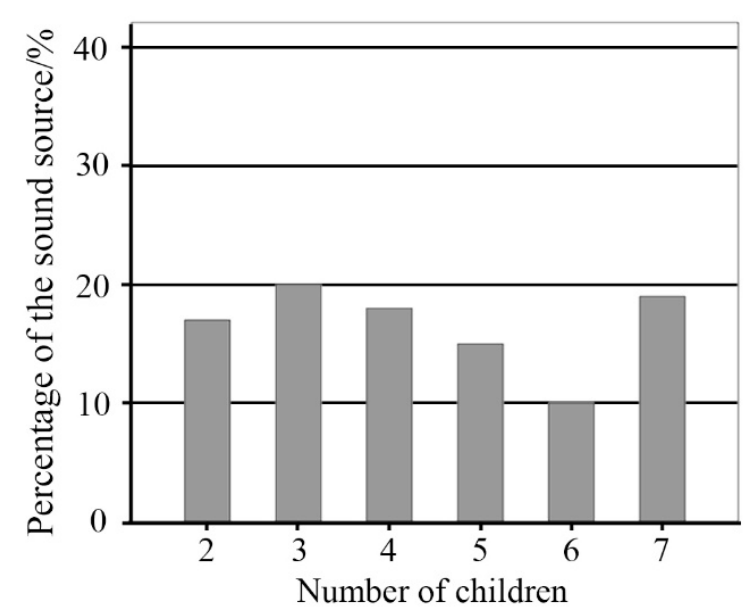

i: sound of children beating an instrument

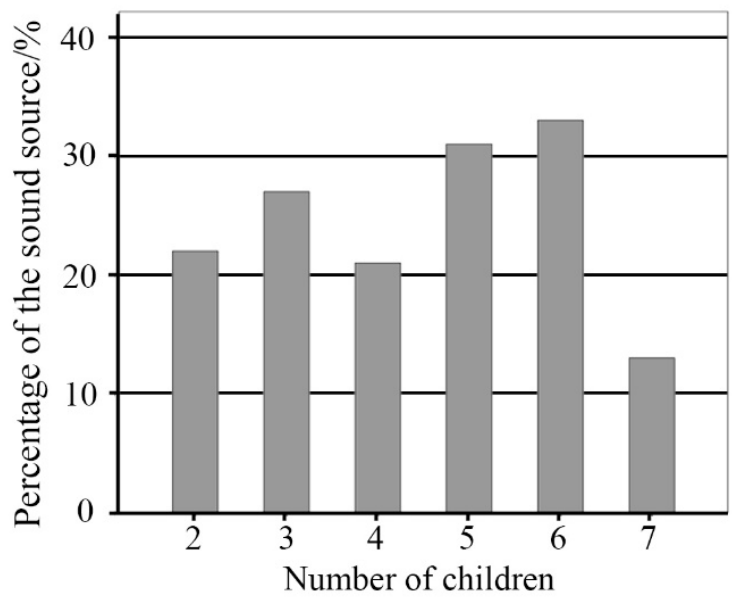

$\mathrm{k}$ : sound of communication among children

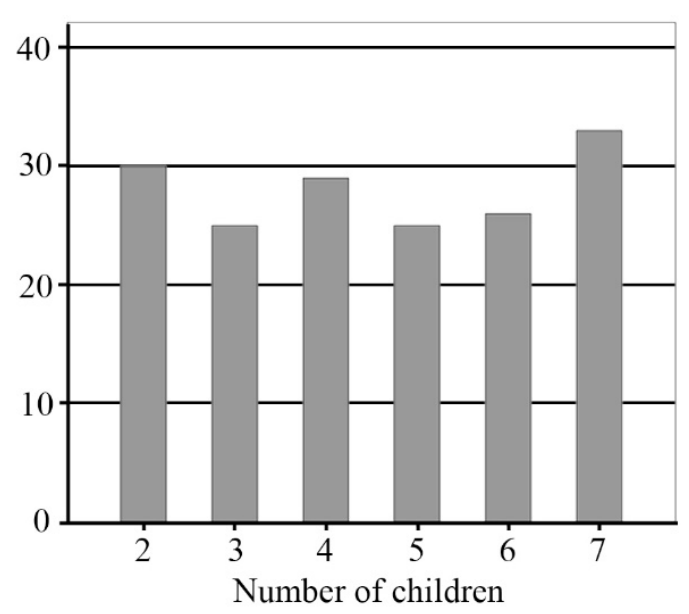

$\mathrm{j}$ : sound of children screaming and crying

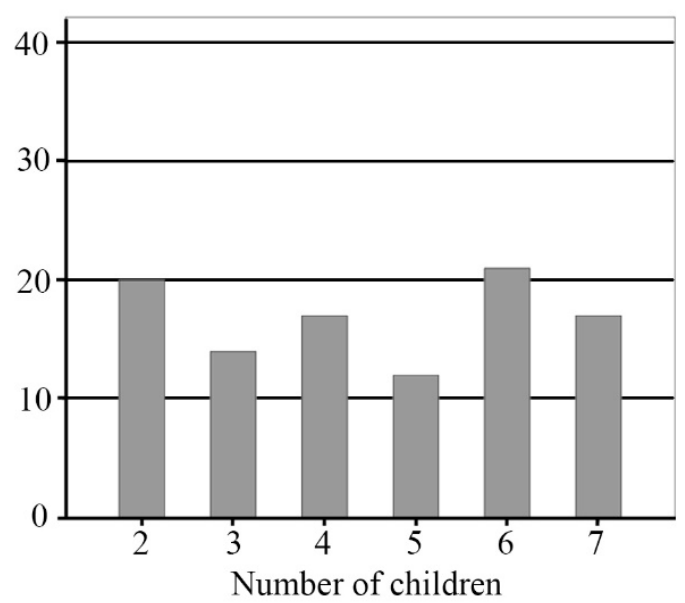

1: sound of communication among children and parents

Fig. 6 Percentage of varied sound sources with different number of children

In terms of the sound of communication between children and parents, the percentage of $l$ sound of communication among children and parents first decreased from $20 \%$ (for two children) to $12 \%$ (for five children) and then increased to $17 \%$ (for seven children). In the observations, parents had a higher probability of communicating with children outside the playground when the number of children was small or large. However, the purpose of communication in these two situations differs. When there were few children, the communication was more likely to be a pretend game to enliven the atmosphere in the playground. When the number was large, the communication was more likely to be to maintain order in the playground.

\subsection{Effect of children's related sound environment on acoustic comfort}

In this section, the effect of sound level and sound sources on acoustic comfort is explored, to determine how to control the number of children to improve the acoustic comfort in a fast-food restaurant.

3.3.1. Effect of SPL on acoustic comfort. Some previous studies have pointed out that the SPL in a fast-food restaurant is generally no more than 80dBA [45]. However, in the present study, sounds of more than $80 \mathrm{dBA}$ were usually related to children, which may influence the evaluation of the acoustic comfort of diners. While with an increase to the Max SPL, the acoustic comfort was significantly reduced. However, due to the distribution of the Max SPL, it is difficult to judge the correlation between acoustic comfort and Max SPL. Therefore, in this section, the relationship between acoustic comfort and the duration of Max SPL exceeding 80dBA is analysed within 15 minutes. The following paragraph uses the OVER 80 to represent the Max SPL that exceeds 80dBA. The duration of OVER 80 is taken as the basis of analysis. For example, if the OVER 80 is measured for 47 seconds in 15 minutes, its duration is in the 30- to 60-second group.

In Fig. 7, the regression analysis shows that there is a significant linear correlation between 
acoustic comfort and the duration of OVER80, with $R^{2}=0.880, p<0.001$. When the duration of OVER 80 is 0 , the acoustic comfort is 3.4. With the increase in duration, acoustic comfort decreases. When it reaches $1 \mathrm{~min} 30 \mathrm{sec}$, the acoustic comfort is 2.5 . The average acoustic comfort decreased by 0.3 every 30 seconds. When the duration is between $1 \mathrm{~min} 30$ secs and $4 \mathrm{~min}$, the acoustic comfort shows a wave. The average acoustic comfort is 2.6 , with the highest acoustic comfort at 2.9 and the lowest at 2.2. Subsequently, the acoustic comfort demonstrated a decreasing trend with the increase in duration. Despite some fluctuations, it was maintained at approximately 1.6. Once the duration exceeded $7 \mathrm{~min}$, the acoustic comfort decreased to 1.2 , which is close to a very uncomfortable degree.

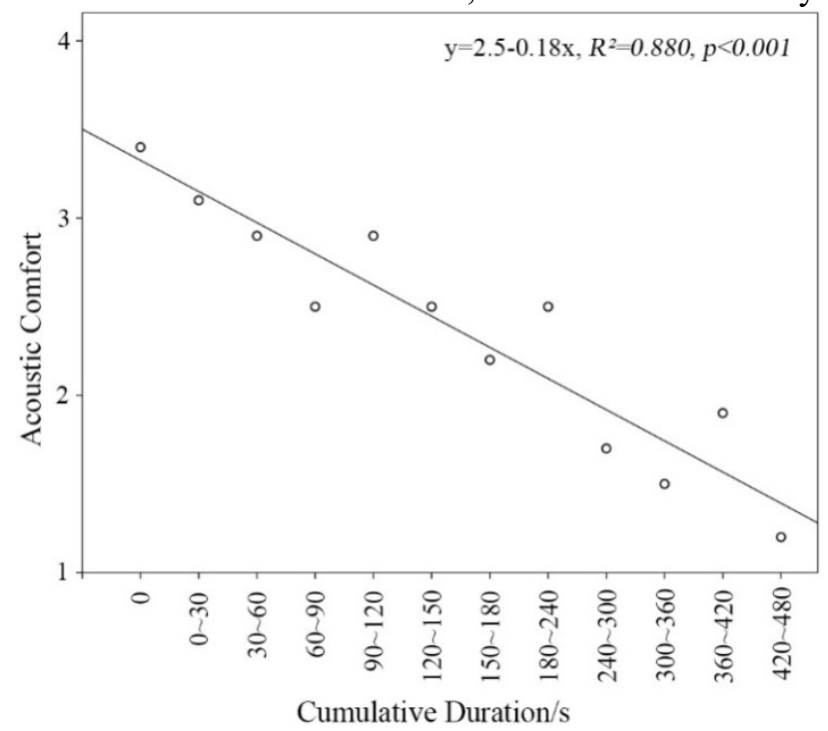

Fig. 7 Effect of duration time of the SPL exceeding 80dBA on acoustic comfort

When the duration is less than $1 \mathrm{~min} 30 \mathrm{secs}$, much of OVER 80 occurs in the form of a sudden rise (Fig. 8a). A sudden rise in the SPL can easily elicit negative emotions, such as irritability and shock. As a result, the acoustic comfort decreased significantly at this stage. When the cumulative duration is $1 \mathrm{~min} 30 \mathrm{sec}-4 \mathrm{~min}$, OVER80 will appear more continuously (Fig. 8b). Although the duration increases, the sudden increase in SPL decreased. Therefore, at this stage, although the acoustic comfort fluctuates, the overall trend is stable. On the other hand, when the duration exceeds $4 \mathrm{~min}$, OVER80 continues to appear (Fig. 8c), and the influence of the SPL on acoustic comfort becomes more obvious.

Combined with Figs. 3 and 4 (section 3.1.1), the findings demonstrate that when there are fewer children, the Max SPL is higher, but the average SPL is lower, and the possible duration of OVER80 is shorter. When there are more children, the opposite is true. In this case, the Max SPL is relatively low, but the average SPL is higher, indicating that the possible duration of OVER80 is longer. Fig. 9 illustrates the effect of the number of children on average acoustic comfort of participants. As shown in Fig. 9 when the number of children was four or six, the average acoustic comfort of participants was maintained at about 2.6. However, when the increase in the number of children increased to seven or eight, the acoustic comfort decreased to between 1.7 and 1.8.

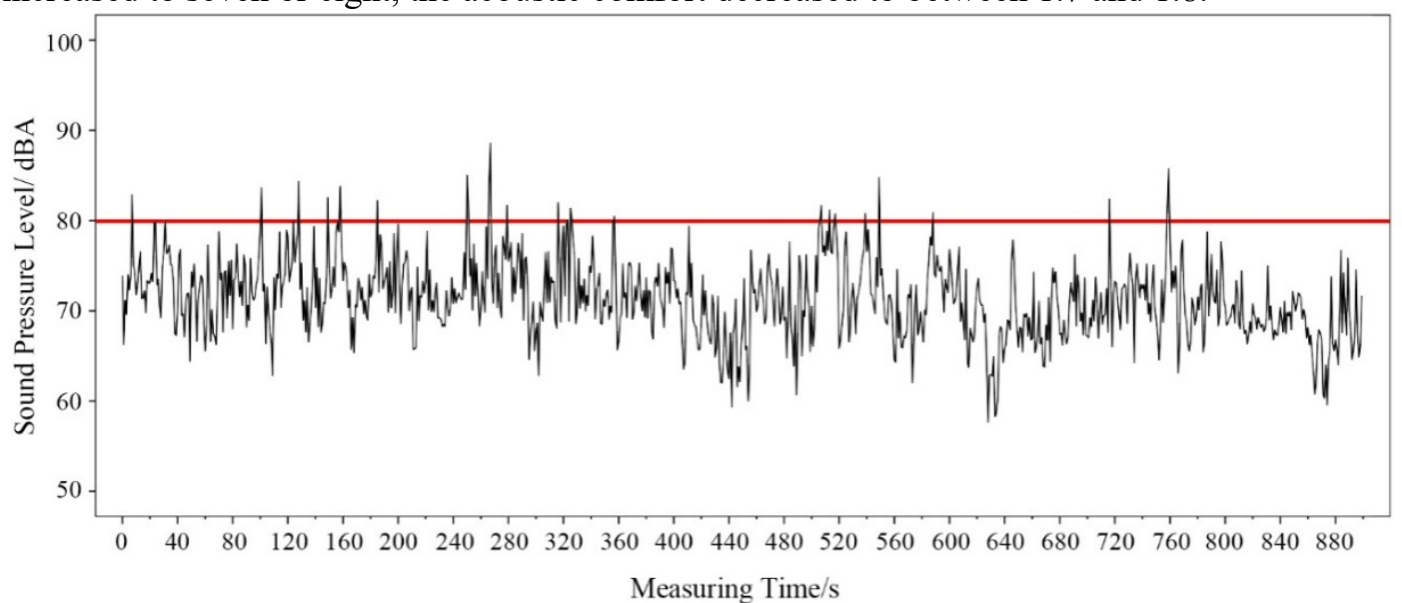

(a) 


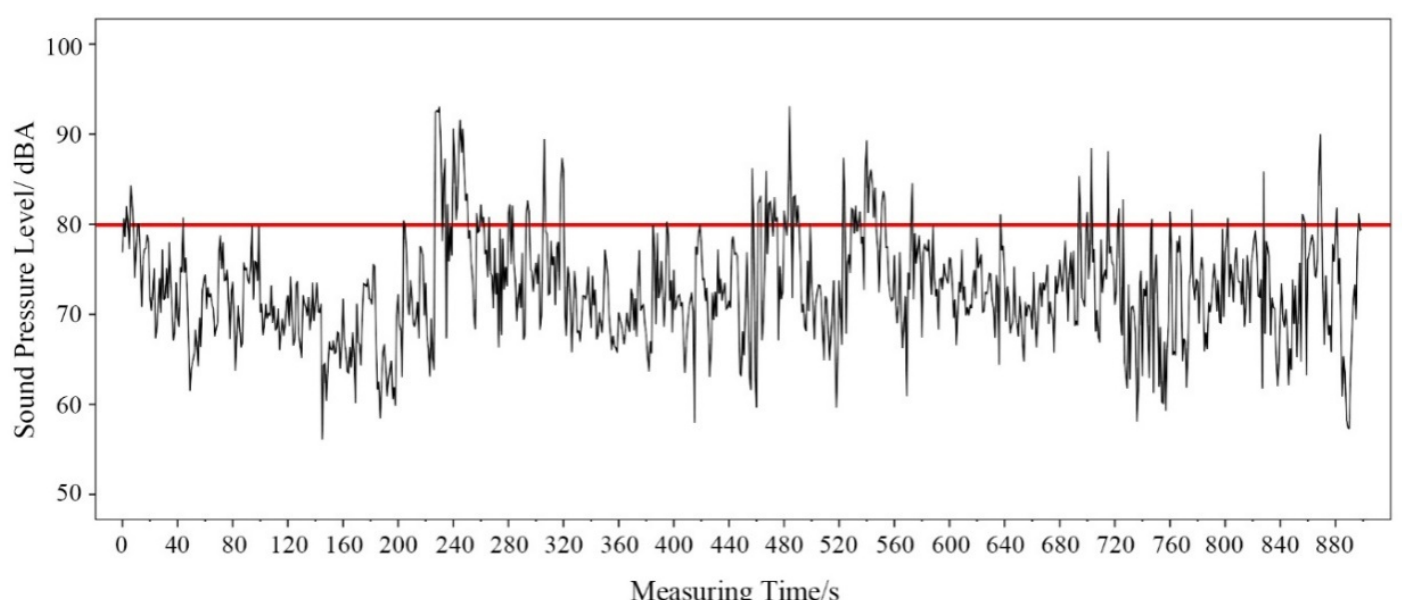

(b)

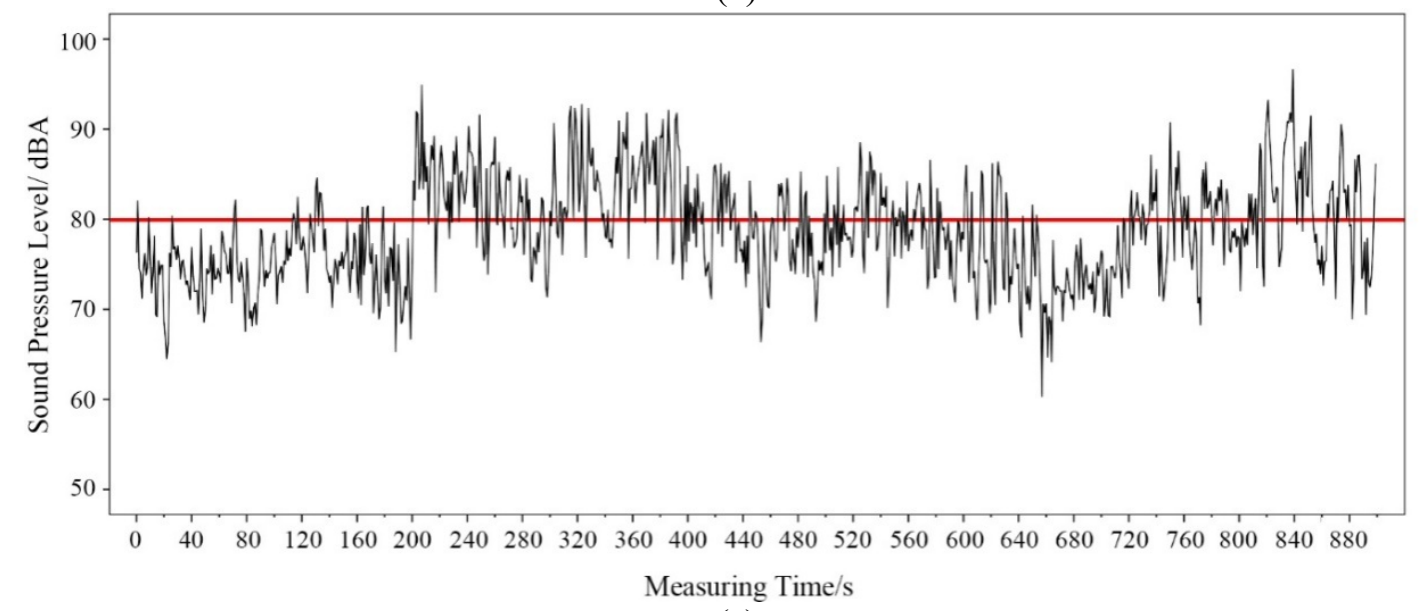

(c)

Fig. 8 Duration of OVER80: (a) less than $1 \mathrm{~min} 30 \mathrm{sec}$; (b) between $1 \mathrm{~min} 30 \mathrm{sec}$ and $4 \mathrm{~min}$; (c) more than $4 \mathrm{~min}$

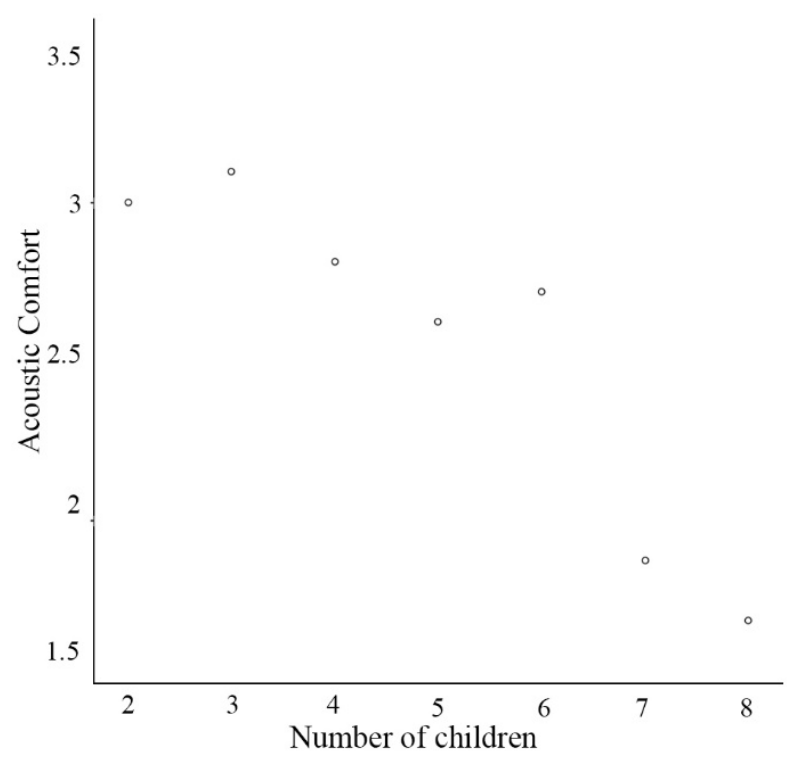

Fig. 9 Effect of the number of children on acoustic comfort

3.3.2. Effect of sound sources on acoustic comfort. An interesting phenomenon is found by the statistical analysis of the most influential sound sources. Thirteen common sound sources were listed in the questionnaire (Table 2), but only nine of the sound sources in the item 'Sound sources that have the greatest impact on you'. Four of the nine sound sources came from the restaurant, accounting for $23 \%$; and five sound sources were related to the playground, accounting for $77 \%$. This result demonstrates intuitively that in this space, the influence of the sound source related to 
the playground is not negligible. There are also obvious differences in the percentages of the nine sound sources. As seen in Fig. 10, the largest percentage is the sound source $j$-child screaming and crying, accounting for $38 \%$. The second-largest is the sound source $k$-children communicate sound, at $24 \%$. The percentage of sound sources a-background music and f-customers communicating with each other is significantly lower than the first two items, at $10 \%$ each. The other five sound sources account for an average of $4 \%$.

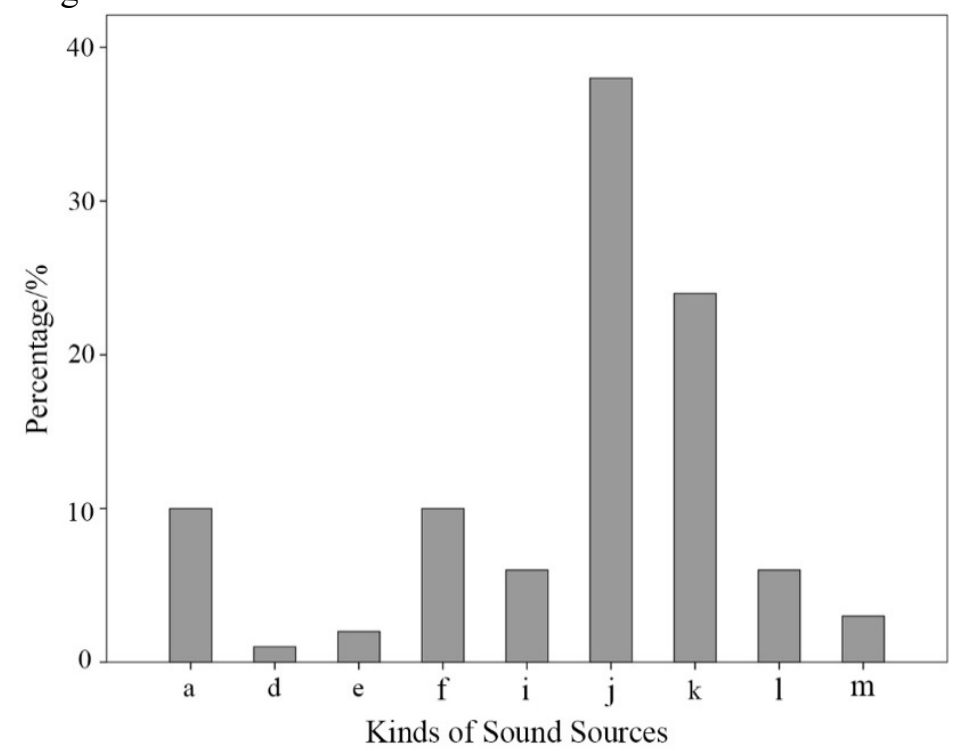

Fig. 10 Percentage of various sound sources: a. Background music; d. sound of table and chair friction; e. sound of communication between staff and customers; f. sound of communication between customers; $i$. sound of children beating instruments; $j$. sound of children screaming and crying; $\mathrm{k}$. sound of communication among children; 1 . sound of communication among children and parents; $\mathrm{m}$. sound of communication among parents.

Although a-background music and f-sound of communication between customers have a relatively large influence on people, the correlation test demonstrated that they have no significant correlation with acoustic comfort, at $p>0.01$. Simultaneously, there is no significant correlation between acoustic comfort and other sound sources from the restaurant, at $p>0.01$. Thus, although some of the sound sources from the restaurant may have some influence on acoustic comfort, they will not lead to a significant decrease or increase in acoustic comfort in the fast-food restaurant with a playground set-up. With the change in the number of children, there is no significant change in sound sources associated with the playground: $i$-sound of children beating instrument, $l$-sound of communication among children and parents, and $m$-sound of communication among parents. Meanwhile, there is no significant correlation between these sound sources and acoustic comfort $(p>$ 0.01 ).

The analysis demonstrated that the single source $j$-sound of children screaming and crying or $k$-sound of communication among children has little effect on acoustic comfort, but the combination of the two sources has an obvious effect on acoustic comfort. This may be because each sound source appears more dispersed when the effects on sound comfort of these two sound sources are calculated separately, and the two sound sources appear more continuous after the two sources are combined, which has a greater impact on acoustic comfort. Therefore, the sources $j$-sound of children screaming and crying and $k$-sound of communication among children are combined into one sound source for analysis. The effect of the sources $j$-sound of children screaming and crying and $k$-sound of communication among children on acoustic comfort is linear, $R^{2}=0.827, p<0.05$. As seen in Fig. 11, when the percentage of the sources $j$-sound of children screaming and crying and $k$-sound of communication among children is less than $20 \%$, the acoustic comfort is 3.3 . When the percentage is less than $30 \%$, the acoustic comfort is 2.8 . At this stage, the acoustic comfort decreased significantly. As the percentage of the sources $j$-sound of children screaming and crying and $k$-sound of communication among children increased from 30\% to $60 \%$, the acoustic comfort demonstrated a slowly decreasing trend. Once the percentage exceeded $60 \%$, the acoustic comfort fluctuated but remained stable at approximately 2.3 . 


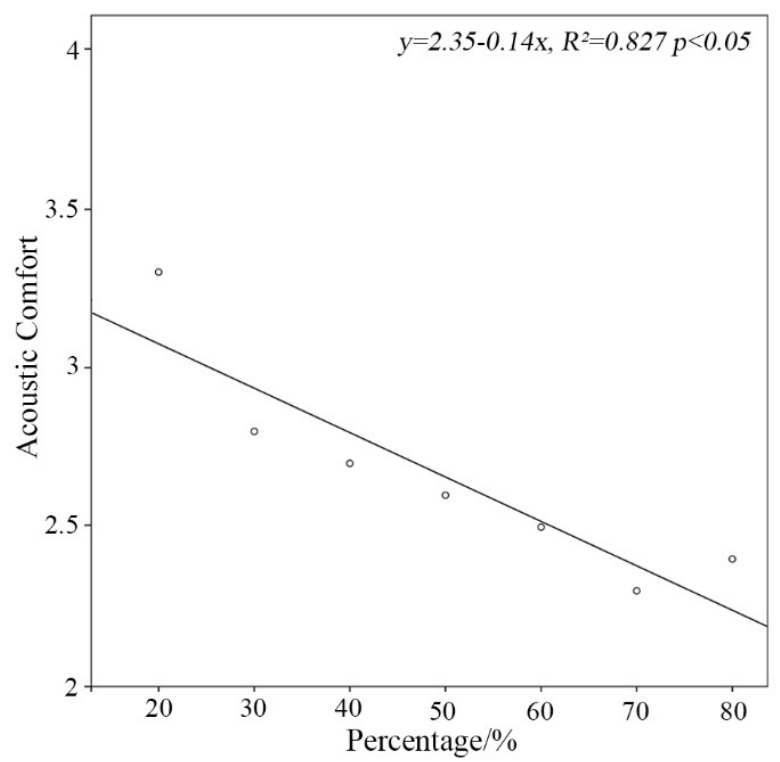

Fig. 11 Effect of the sources $\mathrm{j}$-sound of children screaming and crying and k-sound of communication among children on acoustic comfort

As observed in Fig. 6 (Section 3.2), the percentage of sources for the $j$-sound of children screaming and crying and $k$-sound of communication among children first increases and then decreases slightly with the increase in the number of children, with a percentage of $50 \%-59 \%$ for five to seven children. In combination with Fig. 11, it can be inferred that with the increase in the number of children, the acoustic comfort decreases gradually. This result was also consistent with the results in Fig. 9.

\section{CONCLUSIONS}

Based on measurements, observations, and questionnaires, this study has examined the influence of a children's playground on the sound environment in a fast-food restaurant. The conclusions are as follows.

First, the change in the average SPL is related to the number of children, but not linearly. As the number of children increases, the average SPL increases rapidly and then stabilises. A total of four children is the boundary point between two changing trends. When there are fewer than four children, the SPL increases the fastest at $2.8 \mathrm{dBA} / \mathrm{child}$; the Min SPL increases as the number of children increases, with the average of 1.8dBA per child; and the Max SPL also has four children as the boundary point. When there are fewer than four children, the Max SPL retains a higher level of more than 100dBA and then decreases significantly.

Second, some typical sounds, such as the sound of communication among children, first increased and then decreased with the increase in the number of children, with the highest at $33 \%$. While the sound of children screaming and crying fluctuated from $25 \%$ to $33 \%$ with the change in the number of children, the sound of children beating instruments remained stable at an average of $17 \%$.

Finally, SPL and sound sources can effectively influence the sound environment in terms of acoustic comfort. There is a linear correlation between the variation of acoustic comfort and the duration of OVER 80. With the increase in Max SPL, acoustic comfort reduced from 3.4 to 1.2. The effect on the acoustic comfort of a duration of OVER80 is divided into three stages. It begins with a sharp decline, then fluctuates, before gradually falling to a very uncomfortable level. With the increase in the number of children, acoustic comfort showed a decreasing trend, with 2.1 for three children and 1.6 for eight children. The change to acoustic comfort is correlated with children screaming and communicating. With the increased percentage of sources $j$-sound of children screaming and crying and $k$-sound of communication among children, acoustic comfort first decreases and then stabilises with the change from 3.3 to 2.3 .

The limitations of this study are, first, that it only examined a restaurant with a fixed children's playground, and of the fast-food restaurant type. The maximum number of children in the playground was ten, and the number studied in this paper ranged between two and eight children aged three to six. Thus, this paper does not cover cases of more than eight children. In terms of gender combinations, this study examined gender combinations of three and four. A different 
number of children and different gender combinations, and so on, may have different effects on the sound environment, and this will be examined in future studies.

\section{Acknowledgements}

This study was supported by the National Natural Science Foundation of China (51878210 and 51678180).

\section{References}

[1] Canziani, B.F., Almanza, B., Frashjr, R.E., et al., Classifying restaurants to improve usability of restaurant research, Intern. J. Contemp. Hospit. Man. 28 (7) (2016).

[2] Dong, X., Hu, B., Regional difference in food consumption away from home of urban residents: a panel data analysis, Agric. \& Agric. Sci. Proced. 1 (1) (2010) 271-277.

[3] Ariffin, H.F., Bibon, M.F., Abdullah, R.P.S.R., Restaurant's atmospheric elements: what the customer wants, Procedia - Soc. Behav. Sci. 38 (2012) 380-387.

[4] Stewart, H., Blisard, N., Bhuyan, S., et al., The demand for food away from home: fullservice or fast-food? Agric. Econ. Rep. (2004).

[5] Heung, V.C.S., Gu, T.M. Influence of restaurant atmospherics on patron satisfaction and behavioral intentions. Int. J. Hosp. Man. 31 (4) (2012) 1167-1177.

[6] Chen, X., Kang, J., Acoustic comfort in large dining spaces. App. Acoust. 115 (2017) 166172.

[7] Wansink, B., Van, I.K., Fast food restaurant lighting and music can reduce calorie intake and increase satisfaction, Psych. Rep. 111 (1) (2012) 228.

[8] Spence, C., Noise and its impact on the perception of food and drink, Flavour 3 (1) (2014) 9.

[9] Carvalho, F.R., Van Ee, R., Rychtarikova, M., et al., Using sound-taste correspondences to enhance the subjective value of tasting experiences, Front. Psych. 6 (2015) 1309.

[10] Xi, W., Liang, R., Tanga, E.K., More than words: do emotional content and linguistic style matching matter on restaurant review helpfulness?, Int. J. Hosp. Man. 77 (2018) 438-447.

[11] Zhang, S., Meng, Q., Kang, J., The influence of crowd density on evaluation of soundscape in typical Chinese restaurant, Inter-noise and Noise-Con Congress and Conference Proceedings, 2016.

[12] Chen, B., Kang, J., Acoustic comfort in shopping mall atrium spaces: a case study in Sheffield Meadowhall, Archit. Sci. Rev. 47 (2004) 107-114.

[13] Meng, Q., Kang, J., Influence of social and behavioural characteristics of users on their evaluation of subjective loudness and acoustic comfort in shopping malls, PLOS ONE 8 (1) (2013) e54497.

[14] Hannah, L., Sound and the Restaurant Environment, McGraw-Hill, 2004.

[15] Wansink, B., Ittersum, K.V., Fast food restaurant lighting and music can reduce calorie intake and increase satisfaction, Psychol. Rep. 111 (1) (2012) 228.

[16] North, A.C., Shilcock, A., Hargreaves, D.J., The effect of musical style on restaurant customers' spending, 35 (5) (2003) 712-718.

[17] Shi, J., Qin, G., Wu, J. Restaurant's Lampblack machine and fan noise nuisance case study, North. Envir. (2013).

[18] Meng, Q., Zhang, S., Kang, J., Effects of typical dining styles on conversation behaviours and acoustic perception in restaurants in China, Build. Envir. 121 (2017) 148-157.

[19] Leccese, F., Tuoni, G., Salvadori, G., et al., An analytical model to evaluate the cocktail party effect in restaurant dining rooms: a case study, App. Acoust. 100 (2015) 87-94.

[20] Ohri-Vachaspati, P., Isgor, Z., Rimkus, L., et al., Child-Directed Marketing Inside and on the Exterior of Fast Food Restaurants, American Journal of Preventive Medicine. 48(1)(2015)22-30. [21] Zhou, Z., Sun, X., Xiang, Y., et al., Peer interaction and loneliness in middle childhood: a cross-lagged analysis, Psych. Sci. 30 (6) (2007) 1309-1313.

[22] Walker, S., Irving, K., Berthelsen, D., Gender Influences on Preschool Children's Social Problem-Solving Strategies, The Journal of Genetic Psychology. 163(2)(002)197-209.

[23] Benenson, J., Apostoleris, N., Parnass, J., The organization of children's same-sex peer relationships, New Direct. Child Adolesc. Dev. $81(2010,1998)$ 5-23.

[24] Leaper, C., Influence and involvement in children's discourse: age, gender, and partner 
effects, Child Dev. 62 (4) (2010) 797-811.

[25] Fabes, R.A., Martin, C.L., Hanish, L.D., Young children's play qualities in same-, other-, and mixed-sex peer groups, Child Dev. 74 (3) (2010) 921-932.

[26] Hamza, A. Children's play behavior in an outdoor play setting: case study in Hadana Pusat Islam, U.S.M, Chinese Research Institute of Construction Management (2010) 537-547.

[27] Liu, S., Meng, Q., Kang, J., Effects of children characteristics on sound environment in fastfood restaurants in China, Euronoise 2018.

https://www.researchgate.net/publication/325550433_Effects_of_children_characteristics_on_sou nd_environment_in_fast_food_restaurants_in_China

[28] Meng, Q., Kang, J., The influence of crowd density on the sound environment of commercial pedestrian streets, Sci. Tot. Envir. 511 (2015) 249-258.

[29] Mashburn, A.J., Pianta, R.C., Hamre, B.K., et al., Measures of classroom quality in prekindergarten and children's development of academic, language, and social skills, Child. Dev. 79(3) (2008) 732-749.

[30] Dwyer, G.M., Baur, L.A., Hardy, L.L., The challenge of understanding and assessing physical activity in preschool-age children: Thinking beyond the framework of intensity, duration and frequency of activity, 12(5)(2009)534-536.

[31] Wasik, B.A., Jacobi-Vessels, J.L., Word play: scaffolding language development through child-directed play, Early Child. Educ. J. 45 (6) (2017) 769-776.

[32] Bell, E.R., Greenfield, D.B., Bulotsky-Shearer, R.J., Classroom age composition and rates of change in school readiness for children enrolled in Head Start, Early Child. Res. Quart. 28 (1)

(2013) 1-10.

[33] Yang, W., Kang, J., Acoustic comfort evaluation in urban open public spaces, Applied Acoustics. 66(2)(2005)211-229.

[34] Christie, L.H., Bell-Booth, R.H., Acoustics in the hospitality industry: a subjective and objective analysis, Victoria University of Wellington, New Zealand Centre for Building Performance Research, 2004.

[35] Jaffe, B.F., Lawrence, M., The dynamic range of hearing, Surgical Forum. 17(1966)464.

[36] Zannin, P., Trombetta, H., Marcon, C.C.R., Objective and subjective evaluation of the acoustic comfort in classrooms, App. Ergo. 38 (5) (Sep 2007) 675-680.

[37] Meissner, M., Influence of wall absorption on low-frequency dependence of reverberation time in room of irregular shape, Appl. Acoust. 69 (7) (2008)583-590.

[38] Noone, B.M., Kimes, S.E., Mattila, A.S., et al., The effect of meal pace on customer satisfaction, Cornell Hosp. Quart. 48 (2007) 231-244.

[39] De Pisapia, N., Bornstein, M.H., Rigo, P., et al., Sex differences in directional brain responses to infant hunger cries, NeuroReport 24 (3) (2013) 142-146.

[40] Yu, L., Kang, J., Modeling subjective evaluation of soundscape quality in urban open spaces: an artificial neural network approach, J. Acoust. Soc. Am. 126 (3) (2009) 1163-1174.

[41] Kang, J., Meng, Q., Jin, H., Effects of individual sound sources on the subjective loudness and acoustic comfort in underground shopping streets, Sci Tot. Envir. 435 80-89.

[42] George, D., Mallery, P., IBM SPSS Statistics 23 Step by Step: A Simple Guide and Reference, Routledge, 2016.

[43] Piaget, J., Mays, W., The principles of genetic epistemology, Phil. Quart. 24 (94) (1972) 87.

[44] Jiang, M., An initial research for nonverbal communication development of children aging from 0 to 6, Chinese J. Spec. Ed. 5 (47) (2004) 79-84.

[45] To, W.M., Chung, A., Noise in restaurants: levels and mathematical model, Noise and Health 16 (73) (2014) 368 . 